\title{
Neumomediastino secundario a estornudos
}

\section{Spontaneous pneumomediastinum after sneezing}

Varón de 16 años sin antecedentes médicos de interés que acudió a nuestro centro por cuadro brusco de dolor centrotóracico de carácter opresivo, que empeoraba con la inspiración profunda, acompañado de aumento del perímetro de la zona cervical y supraclavicular bilateral. Refería un cuadro de rinorrea y estornudos de varios días de evolución. En la exploración física destacaba la presencia de crepitación sobre los músculos esternocleidomastoideos, trapecios y zona supraclavicular. La auscultación cardiopulmonar era normal. Se realizó radiografía de torax y TC de cuello y tórax (figura 1) que evidenció un extenso neumomediastino desde pilares diafragmáticos englobando receso pleuropericárdico hasta los planos del cuello, asociado a un importante enfisema subcutáneo. Se instauró tratamiento con analgesia, oxigenoterapia y reposo con progresiva mejoría en los días posteriores hasta total resolución clínica y radiológica.

El neumomediastino espontaneo (NE) se define como la aparición de aire libre en el mediastino sin antecedentes previos de traumatismo, cirugía o procedimientos médicos. Se trata de una patología poco frecuente que se suele presentar de forma brusca con dolor torácico y/o cervical, disnea o síntomas de enfisema subcutáneo. Es más frecuente en adultos jóvenes y solo en un tercio de los pacientes se detectan factores precipitantes (inhalación de drogas, tos, asma, vómitos y actividades deportivas) ${ }^{1,2}$.

Se trata de una entidad que suele presentar buena evolución clínica pero se puede complicar si se presenta asociada a neumotórax 0 si existe patología cardio-pulmonar previa requiriendo tratamientos invasivos y cuidados intensivos.

\section{Bibliografía}

1. Vivek N. lyer, Avni Y. Joshi, Jay H. Ryu. Spontaneous Pneumomediastinum: Analysis of 62 Consecutive Adult Patients. Mayo Clin Proc. 2009; 84:417-421.

2. De la Fuente Aguado J, Roman F, Hernaez JM, Provencio M, de Letona JM. Pneumomediastinum after belching. Lancet. 1990; 336(8727):1390.

\section{Diagnóstico: \\ Neumomediastino secundario a estornudos}

Lucia González-González; Javier de la Fuente Aguado Servicio de Medicina Interna. Hospital POVISA. Vigo

Correspondencia: luciagg82@hotmail.com.

Como citar este artículo: González-González L, dela Fuente Aguado J. Neumomediastino secundario a estornudos. Galicia Clin 2014; 75 (3): 152

Recibido: 28/01/2014; Aceptado: 24/04/2014

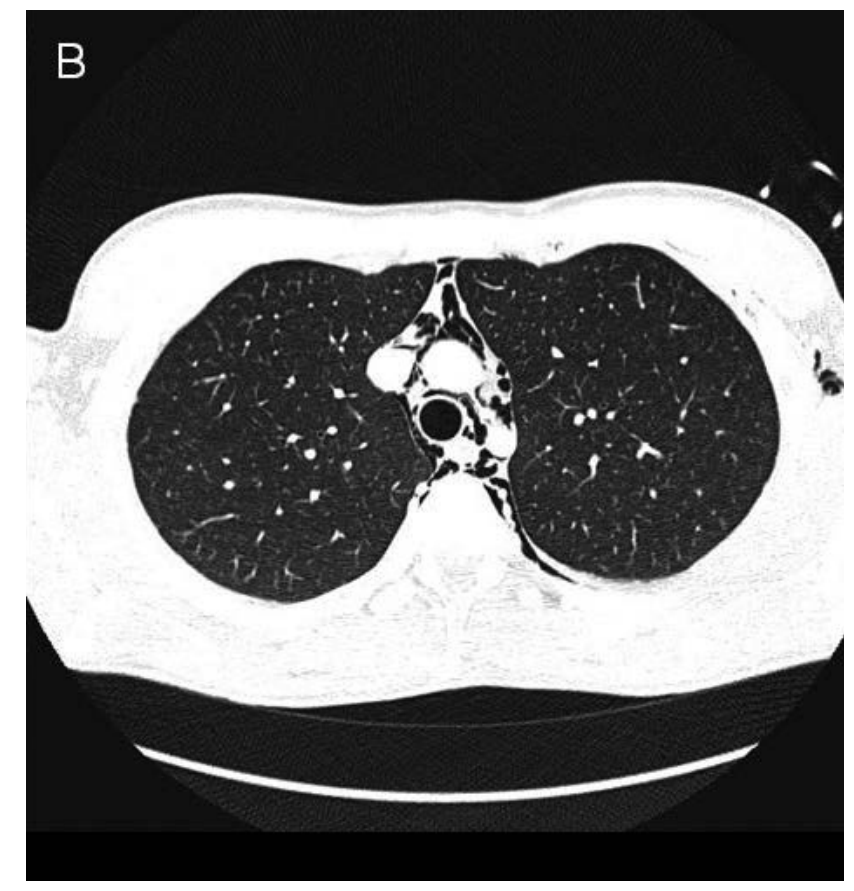

